\title{
DESAFIOS DOCENTES PARA LIDAR COM A INCLUSÃO: ESTEREÓTIPOS EM ANÁLISE
}

THE TEACHING CHALLENGES TO DEAL WITH THE INCLUSION: STEREOTYPES IN

ANALYSIS

\section{CUNHA, Amaranta Cardoso da; FRANÇA, Cibele Reis da Silva da; FELICIO, Michelly \\ Juliane Dias; MOURA Paula Nascimento da Silva \\ Centro Universitário da Fundação Hermínio Ometto - FHO, Araras/SP, Brasil}

\begin{abstract}
RESUMO. Este artigo trata do papel do professor do ensino regular, na desconstrução de estereótipos que vetam a garantia de oportunidades de desenvolvimentos sociais, motores e cognitivos aos alunos com deficiência. Por meio de revisão bibliográfica, buscamos refletir sobre como os professores enfrentam os frequentes rótulos direcionados aos alunos que apresentam variadas dificuldades, sejam elas necessidades educativas especiais e/ou deficiência. Tal reflexão busca evidenciar alguns posicionamentos que podem ser utilizados por esses profissionais para que ocorra a desestruturação deste preconceito atribuído às peculiaridades de cada sujeito, dessa forma contribuindo para o ensino de qualidade para todos, com a igualdade e a equidade que são asseguradas pela legislação brasileira.
\end{abstract}

Palavras-chave: educação, inclusão, estereótipos.

\begin{abstract}
This article deals with the role of regular education teacher, to the deconstruction of stereotypes that denies the guarantee of opportunities of social, motor and cognitive developments to students with disabilities. Through a bibliographical review, it seeks to reflect on how teachers face the frequent labels directed to students that present various difficulties, whether special educational needs and / or disabilities. Such reflection seeks to highlight some positions that can be used by these professionals so that the destructuring of this prejudice attributed to the peculiarities of each subject can occur. Thus, contributing to quality education for all, with equality and equity ensured by Brazilian legislation.
\end{abstract}

Keywords: education, inclusion, stereotype.

\section{INTRODUÇÃO}

Este trabalho tem por objetivo explorar a atuação docente como subsídio para que ocorra a desconstrução de estereótipos na educação inclusiva e salientar alguns posicionamentos que podem ser usados para o alcance desse propósito, com vistas a proporcionar a todos os alunos pleno desenvolvimento, trabalhando com suas condições e respeitando suas limitações.

O Brasil tem uma das melhores legislações sobre inclusão, reconhecida internacionalmente. Nessa legislação, o aluno com deficiência tem direito de frequentar preferencialmente o ensino regular (LDB LEI N9394/96, art. 58). Mas o fato é que, na grande maioria das instituições, a inclusão acontece apenas socialmente, pois pedagogicamente, este aluno é isolado do processo de ensino-aprendizagem, segregando-o. Como afirma Mantoan (2015), os sistemas escolares relutam muito em mudar de direção porque também estão organizados em um pensamento que recorta a realidade, que permite dividir os alunos em normais e com deficiências. Ao passo que constrói o rótulo que os definirá socialmente, não refletindo o que são, mas sim as diferenças que possuem. 


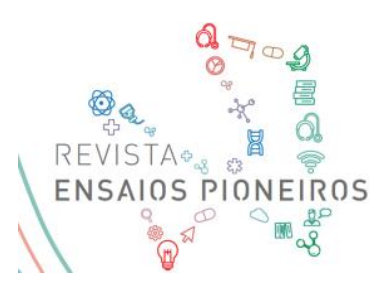

A inclusão implica em uma mudança de perspectiva educacional, isto significa transformar-se, questionar a sua própria prática, rever os seus conceitos, se reeducar e se reinventar. Porém, essa postura flexível é um tanto negligenciada no meio escolar, em que o professor ainda é considerado o detentor do conhecimento. Em vista disso, a inclusão promove uma crise de identidade institucional, que desestabiliza a identidade fixada do professor e, com isso, faz ser revista a identidade fixada ao aluno (MANTOAN, 2015).

O olhar do professor para com seu aluno colabora na mudança de paradigma escolar e com o rompimento de padrões sociais, e é por esse motivo que a educação inclusiva questiona "teorias e práticas que têm como foco o aluno ideal" (FERNANDES, 2007, p.16). Assim, é preciso que o professor compreenda que cada aluno é único e que a educação deve ser construída com o aluno, levando em conta as suas competências e os seus limites, em concordância com Antunes (2008, p.20) quando argumenta que precisamos aceitar "[...] que os seres humanos são essencialmente diferentes e que essas diferenças jamais podem servir de pretexto para estabelecer hierarquia entre melhores e piores $[\ldots]$ "..

Em vista disso, investigamos estratégias utilizadas pelos professores que podem favorecer essa mudança, cientes, contudo, de que cada escola e cada aluno são únicos e que não há um modelo a ser seguido. Na primeira parte, abordamos os marcos histórico sobre a inclusão e seus protagonistas. Na segunda parte, discutimos a construção de estereótipos relacionados aos alunos com necessidades educativas especiais e/ou deficiência e seus impactos. Por fim, na terceira parte, apresentaremos reflexões sobre o papel do professor e a necessidade da sua contribuição na desconstrução de estereótipos.

\section{METODOLOGIA}

Este estudo foi realizado por meio de revisão bibliográfica, buscando investigar sobre como os estereótipos são construídos e se tornam empecilhos para que a educação inclusiva aconteça em sua plenitude. Para isso, foram considerados como fontes norteadoras documentos oficiais e artigos científicos de especialistas sobre o tema. Em especial, destacamos a contribuição de Mantoan (2006; 2017[online]), autora de referência para a educação inclusiva, além de Crochík (1997; 2012), estudioso do preconceito, dentro de uma visão da Teoria Crítica da Sociedade.

\section{RESULTADOS E DISCUSSÃO}

\section{Marcos histórico e seus protagonistas}

Ao longo da história, existiram várias lutas travadas pelas minorias, com o intuito de reivindicar seus direitos, a igualdade e o respeito dentro da sociedade. O processo de inclusão escolar é uma delas. Assim, esta primeira sessão aborda, em ordem cronológica, marcos históricos e seus protagonistas que iniciaram o movimento inclusivo, conquistando, no decorrer dos anos mais espaço na sociedade.

No Brasil, foi o jovem José Álvares de Azevedo que marca um período de início dessa luta em 1854. Com deficiência visual de nascença, aos 10 anos foi enviado para o Real Instituto dos Meninos Cegos de Paris, na França. Já formado, ele retorna ao Brasil com a intenção de exercer uma educação humanitária com deficientes visuais, difundindo em todo o país o sistema braile. Foi por intermédio do pai de uma de suas alunas, que era médico da corte, que surgiu a chance de mostrar seu trabalho para o imperador D. Pedro II e propor a construção do Imperial Instituto dos Meninos Cegos, que foi pioneira na educação especial da América Latina. Em 
1891, instituto mudou seu nome para Instituto Benjamin Constant, como permanece até hoje. José Álvares de Azevedo faleceu seis meses antes de iniciarem as atividades do Instituto (BRASIL, 2016).

O francês E.Huet, diretor do Instituto dos Surdos-Mudos de Bourges, na França em 1855, veio ao Brasil com o projeto de construção do Instituto dos Surdos Mudos -(INES), instituição voltada à educação dos surdos, por meio da língua de sinais. Tal projeto foi apresentado ao imperador D. Pedro II, que aprovou o projeto, e o instituto iniciou seus trabalhos em 1856 e continua a atuar como órgão do Ministério da Educação (BRASIL, 2015).

Em 1926, no Rio Grande do Sul, os professores Thiago Wurth e Johanna Wurth fundaram o Instituto Pestalozzi, a primeira instituição brasileira não governamental voltada a pessoas com deficiência mental, hoje denominada como deficiência intelectual (INSTITUTO PESTALOZZI, [2017]). Entretanto, o movimento Pestalozzi ganhou força com a educadora e psicóloga russa Helena Antipoff que criou, em 1932, a Sociedade Pestalozzi de Minas Gerais e, também, por sua iniciativa, em 1935 foi criado o Instituto Pestalozzi em Belo Horizonte. Em 1945, foi fundada a Sociedade Pestalozzi do Brasil na cidade do Rio de Janeiro, onde ela realizou experiências com alunos superdotados (BRASIL, 2005).

Nesse contexto, que coincide com o fim da Segunda Guerra Mundial em 1945, foi criada a ONU (Organização das Nações Unidas) por líderes de diversos países, que entenderam que somente juntos poderiam construir um futuro melhor, lutando para que jamais acontecesse novamente as atrocidades contra o ser humano ocorridas no período da guerra. Em 1948, foi proclamada, pela Assembleia Geral das Nações Unidas, a Declaração Universal dos Direitos Humanos. Nela estão descritos e garantidos direitos de todas as pessoas ao redor do mundo (BRASIL, 2009).

Voltando à história brasileira, Beatrice Bemis se espantou ao chegar ao Brasil e não encontrar instituições que se dedicassem integralmente ao desenvolvimento das pessoas com deficiência. A partir disto, a norte-americana, membro do corpo diplomático, mãe de uma menina com Síndrome de Down e fundadora de diversas Associações de Pais e Amigos nos EUA, instigou um grupo de pais, amigos, profissionais da área como médicos e professores, a fundarem a primeira APAE do Brasil em 1954 (APAE BRASIL, [2017]).

Quanto às ações oficiais, a primeira Lei de Diretrizes e Bases (LDB) foi promulgada em 1961, na Lei $\mathrm{n}^{\circ}$ 4024/1961, e nela foi instituído o atendimento a pessoas com deficiências, sempre que possível, no ensino regular (BRASIL, 1961). A LDB foi alterada pela Lei $\mathrm{n}^{\circ}$ 5692/1971 e, nesta nova versão, propõe tratamento especial às pessoas com deficiências, contrariando sua primeira versão (BRASIL, 2005).

O Grupo-Tarefa de Educação Especial do MEC foi responsável pela construção da primeira proposta da educação especial brasileira em 1973 (MANTOAN, [2017]). No mesmo ano foi criado o CENESP - Centro Nacional de Educação Especial, com o intuito de expandir e melhorar o atendimento a pessoas com deficiências (BRASIL, 1973).

Novamente no contexto internacional, a Organização das Nações Unidas proclamou o ano de 1981 como o Ano Internacional das Pessoas Deficientes. No ano seguinte foi aprovado o Programa de Ação Mundial para as Pessoas com Deficiência, na Resolução 37/52. A meta corresponde ao alcance da igualdade e a participação plena das pessoas com deficiência na vida social e no desenvolvimento econômico. Já na Resolução 37/53 é proclamada a Década das Nações Unidas para as Pessoas com Deficiência (1983-1992), período para a execução do Programa de Ação Mundial (ASSEMBLÉIA GERAL DAS NAÇÕ̃ES UNIDAS, 1982).

No Brasil, a partir da Constituição Federal de 1988, ficou estabelecido que a educação é um direito de todos, assim como a igualdade de condições de permanência na escola e a oferta 


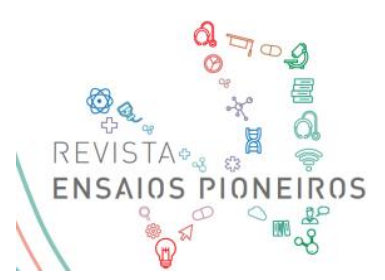

de atendimento educacional especializado, preferencialmente na rede regular de ensino (BRASIL, 1988).

Em novembro de 1989 foi realizada pela Assembleia Geral das Nações Unidas a Convenção sobre os Direitos das Crianças, oficializada como lei internacional em 1990 e ratificada por 196 países, inclusive o Brasil. Esse é considerado o instrumento de direitos humanos mais aceito na história (ASSEMBLÉIA GERAL DAS NAÇÕES UNIDAS, 1989). O Brasil foi um dos pioneiros em criar uma lei que seguisse seus princípios. Em 13 de julho de 1990 foi sancionado o Estatuto da Criança e do Adolescente, com a finalidade de garantir os direitos e deveres para com este público.Determina também políticas de atendimento e assistência, assim como medidas de proteção e socioeducativas (BRASIL, 2012).

A Conferência Mundial sobre Educação para Todos em Jomtien, Tailândia, em março de 1990, reuniu os representantes das ONU para discutir o direito de toda pessoa à educação, expresso na Declaração Universal dos Direitos Humanos. Com o propósito de ultrapassar as barreiras ainda existentes para que a educação seja igualitária para todos sem exceção, assim foi proclamada a Declaração Mundial sobre Educação para Todos. Entre os objetivos citados, estão a superação da desigualdade educacional, a garantia de igualdade ao acesso escolar a pessoas com deficiência e a eliminação de todo e quaisquer preconceitos e estereótipos na educação (CONFERÊNCIA MUNDIAL SOBRE EDUCAÇÃO PARA TODOS, 1990).

A Unesco, em 1994, realizou a Conferência Mundial sobre Necessidades Educativas Especiais em Salamanca na Espanha, com o objetivo de discutir a atenção educacional aos alunos com necessidades educacionais especiais (BRASIL, 2004). Suas metas trouxeram um novo paradigma para a Educação Inclusiva e é considerada um dos principais documentos mundiais sobre inclusão. No mesmo ano, o Brasil publicava a Política Nacional de Educação Especial, porém o texto propõe a integração institucional, que aceita somente a inclusão de alunos com deficiência que possuam condições de acompanhar as atividades curriculares programadas, excluindo muitos alunos do ensino regular (TODOS PELA EDUCAÇÃO, 2014).

Sancionada em 1996, a LDB nº 9394/96, tem um capítulo específico para a educação especial, garantindo a educação escolar preferencialmente em rede regular de ensino, os serviços de apoio especializado na escola regular quando necessário, o atendimento especializado fora das classes comuns somente quando não for possível a integração; currículos, métodos, técnicas, recursos educativos e organização específica para assegurar o atendimento às necessidades dos alunos (BRASIL, 1996).

A Convenção Interamericana para a Eliminação de Todas as formas de Discriminação contra as Pessoas Portadora de Deficiência, conhecida por Convenção da Guatemala, em 1999, reafirma a igualdade de direitos e liberdades fundamentais das pessoas com deficiência (BRASIL, 1999). Em 2001 entra em vigor o Decreto n³956/2001 assegurando o cumprimento integral das propostas da convenção (BRASIL, 2001).

O Plano Nacional de Educação Lei n 10172/2001, aprovado em 2001, possui 28 metas que abordam melhorias para alunos com deficiência e considera a educação especial como modalidade de ensino e é recomendada a construção de escolas inclusivas, com atendimento a todos (BRASIL, 2001).

Criado em 2007, o Plano de Desenvolvimento da Educação (PDE), tem como razões e princípios o conflito entre a educação regular e a educação especial, impedindo a execução do artigo 206, inciso I da Constituição Federal de 1988, que nos garante a igualdade de acesso e permanência na escola. Nele também é reconhecida a construção histórica de uma cultura escolar excludente e com isso uma dívida com a sociedade que deve ser suprida (BRASIL, 2007). Ainda em 2007, é promulgado o Decreto n ${ }^{\circ} 6094 / 07$ que implementa o Plano de Metas Compromisso Todos Pela Educação, em seu artigo 2. ${ }^{\circ}$, inciso IX garante o acesso e 
permanência das pessoas com deficiência no ensino regular, fortalecendo a inclusão (BRASIL, 2007).

Com a criação da Política Nacional de Educação Especial na Perspectiva da Educação Inclusiva, elaborado pelo grupo de trabalho nomeado pela Portaria Ministerial n. ${ }^{\circ 555, ~ e m ~ 2008, ~}$ o Brasil passa a ter um documento com o objetivo de garantir ao aluno com deficiência o direito ao acesso, à participação e à aprendizagem no ensino regular, em que suas necessidades educacionais especiais serão atendidas (BRASIL, 2007).

O Plano Nacional de Educação (PNE) foi aprovado pela Lei n. ${ }^{\circ}$ 13005/2014 e estabelece metas para melhoria da educação brasileira nos dez anos seguintes à sua publicação. São vinte metas divididas em quatro grupos. O segundo grupo diz respeito à redução das desigualdades e à valorização da diversidade, a meta quatro prevê o acesso à educação básica e o atendimento educacional especializado preferencialmente na rede regular de ensino, assegurando um sistema de educação inclusivo (BRASIL, 2014).

Desde o primeiro movimento a favor da inclusão no Brasil até os dias atuais passaramse 163 anos. Foram muitas lutas e conquistas, porém ainda temos um longo caminho. Para dar início a este processo, foi primordial a existência de iniciativas individuais e de movimentos sociais que decidiram intervir, buscando assegurar os direitos das pessoas com deficiência, olhando além dos estereótipos. Esse olhar é de suma importância dentro do ambiente escolar para que inclusão seja realizada em sua plenitude. Os professores são os protagonistas nessa mudança, pois ao encarar o aluno como um ser único, compreende que a sua prática deve ser construída individualmente, levando em conta as suas diferentes potencialidades. Acrescentase a isso, que os processos de inclusão escolar estão superando algumas padronizações e compreendendo que disciplinas fechadas em si mesmas e resultados quantitativos favorecem apenas uma parcela de sua clientela. Além disso, tal postura favorece a construção da consciência crítica em todos os alunos sobre a valorização e o respeito à diferença, como defende Antunes:

[...] é essencial que os professores acreditem na educação inclusiva não apenas como um simples "método de trabalho" que dominando passam a aplicar ao seu cotidiano, mas como uma nova maneira de pensar e encarar sua função educativa, a qual passa a assumir como prioridade as relações igualitárias em detrimento às da velha educação marcadas pela prepotência e pela subserviência[...]. (ANTUNES, 2008, p.20)

Estereótipos relacionados aos alunos com necessidades educativas especiais elou deficiências e os prejuízos causados por eles.

Ainda que a legislação apontada na seção anterior estipule a garantia de igualdade de condições para o acesso e permanência na escola, a sociedade ainda é excludente e preconceituosa e isso se reflete nas instituições de ensino.

Atualmente, constata-se na maioria das escolas supostas inclusões das minorias a fim do cumprimento da lei. Nessa inclusão fictícia, permanecem preconceitos relacionados a esses alunos que não correspondem ao ideal. E de acordo com Aquino (2004, p.94), “[...] esta é a fórmula mais segura para a desgraça própria e a alheia: esperar do outro o que você supõe que ele deveria ser ou fazer[...]". Tal conduta impossibilita o reconhecimento do outro, a fim de evitar os reconhecimentos de nossas limitações.

Segundo Mantoan (2015, p.24) “[...] se o que pretendemos é que a escola seja inclusiva, é urgente que seus planos se redefinam para uma educação voltada à cidadania global, plena, livre de preconceitos, que reconhece e valoriza as diferenças [...]". O conceito de aluno ideal traz para a escola um posicionamento rígido frente ao diferente, impossibilitando a experiência 


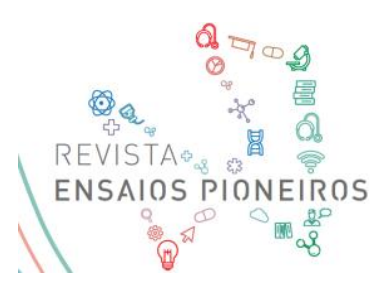

necessária para o rompimento do preconceito, criando um mecanismo de defesa para aquilo que é estranho (CROCHÍK, 2011). Para Mantoan:

\begin{abstract}
O aluno abstrato justifica a maneira excludente de a escola tratar a diferença. Assim é que se estabelecem as categorias de alunos: deficientes, carentes, comportados, inteligentes, hiperativos, agressivos e tantos mais. Por essa classificação é que se perpetuam as diferenças na escola. Por detrás dela é que a escola se protege do aluno, na sua singularidade. (MANTOAN, 2015, p.57-58).
\end{abstract}

Segue-se então utilizando os estereótipos como justificativa para o preconceito. Essas generalizações fixam o indivíduo em um padrão, que limita suas chances de desenvolvimento, pois transformam o indivíduo em sua peculiaridade (CROCHÍK, 1997).

$\mathrm{O}$ acesso do aluno com necessidades educativas especiais e/ou deficiências é cercado por pré-conceitos. Em conformidade com Crochík (1997, p.27) “[...] o pré-conceito pode dizer respeito tanto às percepções, experiências ou conceitos já formulados, quanto às necessidades emocionais existentes antes da nova experiência [...]". Devemos nos atentar para que esses conhecimentos, já formulados, não se tornem obstáculos para o novo, gerando o preconceito que nada mais é que uma ferramenta para se defender de ameaças imaginárias (CROCHÍK, 1997). No cotidiano escolar o pré-conceito, ou seja, o preconceito, encaixa-se neste contexto de proteção: os profissionais pertencentes à instituição não se sentem preparados para o trabalho com as diferenças, tendo em vista que a escola passou anos enquadrando os alunos em um único padrão e excluindo aqueles que não se encaixavam. Isso torna inevitável o sentimento de impotência dos professores de educação especial e educação regular, que acreditam que alunos com deficiência os desviam de seu propósito real, destruindo a rotina, argumentando não saber como ensinar tais alunos (O'BRIEN, 1990).

Há vários fatores que influenciam na construção de estereótipos na escola. O sentimento de despreparo é o que mais aflige os professores. Essa insegurança inicia-se no professor em sua formação, em razão do ensino fragmentado no qual aprende e ensina. Os licenciados acreditam que necessitam ser instruídos para lecionar ao aluno com necessidades educativas especiais e/ou deficiência, com soluções predefinidas para eventuais problemas (MANTOAN, 2015). Essa concepção se direciona para a padronização, o que acaba por levar à exclusão.

Para Mantoan $(2015$, p. 81) "[...] formar o professor na perspectiva da educação inclusiva implica ressignificar o seu papel, o da escola, o da educação e o das práticas pedagógicas usuais do contexto excludente do nosso ensino [...], que possui um sistema fragmentado, que determina o tempo e idade que cada aluno deve adquirir o conhecimento selecionado. Com isso, permite a comparação entre os alunos, deixando de lado as potencialidades de cada um. Essa comparação é perigosa, pois cada indivíduo aprende de formas diferentes e em tempos diferentes, isso não é sinônimo de incapacidade e sim de heterogeneidade. Segundo Mantoan:

O professor inclusivo não procura eliminar a diferença em favor de uma suposta igualdade de alunado - tão almejada pelos que pregoam a homogeneidade das salas de aula. Ele está atento aos diferentes tons das vozes que compõem a turma, promovendo a harmonia, o diálogo, contrapondo-as, complementando-as (MANTOAN, 2015, p.79).

Quando o professor se depara com a inclusão, sem que tenha refletido sobre sua experiência docente, a sensação de incompetência é inevitável. Segue então uma busca incansável para neutralizar este incômodo. Segundo Max Horkheimer e Theodor W. Adorno (1985apud CROCHÍK, 2011), o medo frente ao desconhecido gera a tendência a dominar esse 
desconhecido a partir da atribuição de regularidade aos seus comportamentos. Desta forma, inicia o enquadramento dos alunos tidos como diferentes, cada qual em seu rótulo. Proporcionando segurança ao indivíduo ameaçado, os estereótipos servem de justificativa para a dominação e se tornam obstáculos na experiência entre o professor e o aluno, descartando a oportunidade de transformação que agregaria aprendizagens significativas para ambos (CROCHÍK, 2011).

São muitos os prejuízos causados pelos estereótipos na educação, a discriminação dos indivíduos é um deles. A discriminação é o que ocorre quando o preconceito entra em ação e se manifesta na segregação, que é a separação imaginária ou real de alguém ou de algum grupo, e na marginalização, que é colocar este alguém ou grupo na margem (CROCHIK, 2011). Ambas submetem os indivíduos discriminados a posições inferiores da maioria dominante. Segundo Mantoan:

\begin{abstract}
Por tudo isso, a inclusão é produto de uma educação plural, democrática e transgressora. Ela provoca uma crise escolar, ou melhor uma crise de identidade institucional - que, por sua vez, abala a identidade fixada dos professores e faz que seja ressignificada a identidade fixada do aluno. $\mathrm{O}$ aluno da escola inclusiva é outro sujeito, que não tem uma identidade determinada por modelos ideais, permanentes, essenciais. (MANTOAN 2011, p.35).
\end{abstract}

Em razão disso, é de suma importância a experiência entre os indivíduos para que a não ocorra a construção de preconceitos frente ao diferente, consequentemente desconstruindo os estereótipos na educação e dando ênfase à valorização da diferença, proporcionando às pessoas identidades que as tornam únicas, sem possibilidade de padronização.

\title{
O papel do professor para a desconstrução do estereótipo
}

A educação inclusiva está em pleno desenvolvimento. Aos poucos estamos construindo uma realidade em que a educação é para todos. Concordamos com Mantoan (2015, p.81) "[...] que a inclusão escolar não cabe em uma concepção tradicional de educação. A formação do professor inclusivo requer o redesenho das propostas de profissionalização existentes e uma formação continuada que também muda [...]".

Neste processo de mudança de paradigma educacional, o professor tem grande responsabilidade, em vista que é ele quem tem o contato direto com o aluno, resultando em uma experiência que proporciona transformações para as duas partes, podendo ser positivas ou negativas. É importante pensar que o professor é uma construção social em constante metamorfose. Segundo Brito:

[...] compreensível é pensar que o professor não nasce professor este se constitui. E se constitui não somente como fruto de um diploma ou de uma somatização de conteúdos vistos na sua formação inicial, necessários, reconheço, mas não suficientes. O Professor se constitui, sobretudo como resultado de uma vivência, de um processo de construção social, no qual em interação com outros indivíduos e, em especial, com o aluno, aos poucos vai construindo a sua identidade e a sua competência profissional[...] (BRITO, 2003, p.43).

Nossa legislação prescreve que, a partir da Resolução CNE/CP $n^{\circ} 1 / 2002$, que institui as Diretrizes Curriculares Nacionais para a formação de professores da Educação Básica (BRASIL, 2002), toda formação profissional do professor deve contemplar conhecimentos 


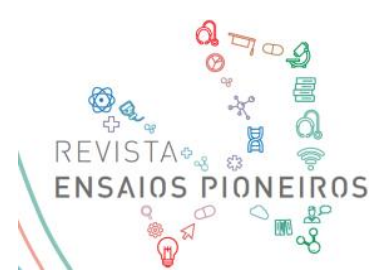

teóricos sobre inclusão, como sustentação para sua prática, que possibilita a fundamentação do pensamento crítico do professor, afastando a concepção da relação educador-educando ser uma relação meramente narradora (FREIRE, 2016), ou seja, o professor como aquele que tudo sabe e ao aluno resta o papel passivo daquele que nada tem a ensinar. Quando essa concepção é enfraquecida, o professor tem a chance de se adicionar ao aluno, "[...] Desta maneira, o educador já não é o que apenas educa, mas o que, enquanto educa, é educado, em diálogo com o educando que, ao ser educado, também educa [...]" (FREIRE, 2016, p.120). Em contrapartida, quando o professor se isola em sua concepção "bancária" (FREIRE, 2016) em defesa de seu ego, do mesmo modo ele se isola da experiência com o outro. Como é apresentado por Lajonquière:

O adulto/civilizado não duvida do que faz pois seria como duvidar de/do "si mesmo" ou "si próprio". Ele apenas "reflexiona sobre sua prática" com vista a aperfeiçoá-la tecnicamente. Assim aprofunda a alienação de/no "si mesmo", enquanto coisifica a criança ou o tempo de sua infância à espera de que alguém ou algum recurso venha a suturar o mal-estar que lhe invade (LAJONQUIÈRE, 2001, p. 52).

O ensino inclusivo propicia benefícios aos professores, tais como a necessidade de reestruturação, questionando-se, buscando novos caminhos e moldando as suas "teorias pedagógicas" (MANTOAN, 2015). Para Karagiannis e Stainback (1999), nessa transformação da profissão do ensino, os professores têm a oportunidade de desenvolver suas habilidades profissionais em uma esfera de coleguismo, de colaboração e de apoio com os atores escolares. A troca de experiências com outros profissionais abre um leque de novas possibilidades de ensino e de aprendizagem.

Uma das premissas da educação inclusiva é não permitir o isolamento do aluno, pois todos devem estar inseridos no processo, segundo a Resolução CNE/CEB no 2/2001, que implementa as Diretrizes Nacionais para a Educação Especial na Educação Básica. Ela estabelece, entre outros objetivos, o dever de matricular todos os alunos, assegurando uma educação de qualidade, apesar de suas peculiaridades (TODOS PELA EDUCAÇÃO, 2014). Para isso, devem ser elaborados meios de abordar a segregação e a marginalização citadas anteriormente, tanto com alunos como com os professores. Reconhecendo o obstáculo, deparamo-nos com um leque maior de possibilidades para superá-lo. Abertos a experiência, há chance de identificação. Como nos apresenta Crochík:

Se é difícil a identificação com as pessoas que conhecemos, tendemos a nos fechar nos pequenos grupos que nos acolhem; a segregação desses pequenos grupos entre si promove o estranhamento; talvez as identificações entre as pessoas nesses pequenos grupos pudessem servir de modelo para as outras identificações. (CHOCHÍK, 2011).

Também é fundamental que o professor assuma um posicionamento de esclarecimento perante a classe sobre a diferença apresentada pelo aluno considerado de inclusão, abrindo espaço para uma discussão das possíveis dificuldades e quais caminhos para superá-las. Sem essa intervenção, os outros alunos podem não entender o processo, causando o afastamento do aluno em questão. Em conformidade com Crochík (2011, p.40) "A oscilação e a dúvida são o nascedouro da experiência; a pergunta das crianças que se repete e nunca se responde guia a curiosidade para o que não conhecemos. São elas - a oscilação, a dúvida e a pergunta - que podem reestabelecer a experiência por negar a certeza do preconceito". 


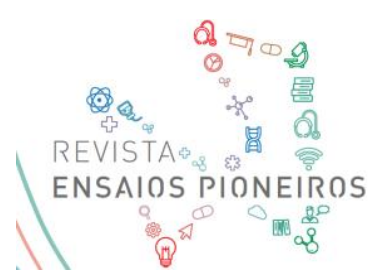

Para Schaffner e Buswell (1999, p. 69) “[...]todos os defensores da melhoria das escolas para melhor atender às diferentes necessidades dos alunos devem unir-se e reconhecer o princípio de que as boas escolas são boas para todos os alunos [...]". Para isso o professor precisa se desconectar do título de detentor de conhecimento e, juntamente com os alunos, construir o processo educativo. Essa postura possibilita várias formas de compreensão e aprendizagem, em conformidade com Mantoan $(2015$, p. 66) " $[. .$.$] vale o que os alunos são capazes de aprender$ hoje e o que podemos oferecer-lhes de melhor para que se desenvolvam em um ambiente rico e verdadeiramente estimulador de suas competências[...]". Assim, essa experiência entre professor e aluno proporciona a desconstrução de estereótipos sobre a inclusão. É através deste contato que ambos se beneficiam, mutuamente os saberes pertencentes a cada um é oferecido ao outro, resultando em reconhecimento, anulando os preconceitos construídos socialmente.

Como afirma Mantoan (2015, p.59) “"...] temos de combater a descrença e o pessimismo dos acomodados e mostrar que a inclusão é uma grande oportunidade para que os alunos, pais e educadores demonstrem as suas competências, os seus poderes e as suas responsabilidades educacionais[...]".

A educação inclusiva requer do professor um olhar crítico para sua própria prática, se redescobrindo como profissional, também redescobrindo seus alunos e reconstruindo o meio educacional, deixando para trás a busca por um padrão, valorizando as diferenças de cada indivíduo. Desta forma eliminando a construções de estereótipos. Segundo Mantoan:

\footnotetext{
Nesses ambientes educativos, ensinam-se os alunos a valorizar a diferença pela convivência com seus pares, pelo exemplo dos professores, pelo ensino ministrado nas salas de aula, pelo clima socioafetivo das relações estabelecidas em toda a comunidade escolar sem tensões, competições, com espírito solidário e participativo. Escolas assim concebidas não excluem nenhum aluno de suas salas, de seus programas, das suas atividades e do convívio escolar mais amplo. São contextos educacionais em que todos têm a possibilidade de aprender frequentando uma mesma e única turma (MANTOAN, 2015, p.66-67).
}

Há ainda quem acredita que a educação inclusiva não passa de uma utopia e este é um dos maiores estereótipos a ser desconstruído, em vista que utópico mesmo é a projeção do aluno ideal, da turma ideal, do professor ideal, da escola ideal, em que todos assumem seus papeis em um imenso sistema padronizado. "[...] As escolas de qualidade são espaços educativos de construção de personalidades humanas autônomas, críticas, espaços onde crianças e jovens aprendem a ser pessoas [...]" (MANTOAN, 2015, p. 66), possibilitando a cada indivíduo ser o que realmente é, além de toda e qualquer especificidade que possa possuir, ao passo que também proporciona ao outro a experiência necessária para que ocorra o reconhecimento com o indivíduo, até então estereotipado, resultando na eliminação do preconceito e valorizando a diferença.

\section{CONCLUSÃO}

A educação inclusiva é um movimento que luta para que todos possam exercer o direito de ter uma educação de qualidade, momentos de acolhimento e valorização das diferenças com valor social, trazendo respeito e cooperação para a vida cotidiana das pessoas.

Muitos foram os que lutaram para que chegássemos ao momento atual. A instituição escolar ainda tem muito que mudar, porém esta mudança consiste em uma transformação sociocultural. Cada instituição deve priorizar a possibilidade de diferenciação, valorizando as 
experiências vividas, as interações entre as pessoas do convívio escolar, da família e da comunidade.

Todos os indivíduos que integram a sociedade necessitam deixar que as experiências do contato com o outro os modifiquem, essa postura talvez possibilite a desconstrução do preconceito frente ao diferente, resultando na eliminação dos estereótipos e das barreiras que o tornam mais frequentes, passando a compreender as necessidades e dificuldades que o outro apresenta. Para isso, contamos com a legislação que nos oferece embasamento para que o direito de todos os cidadãos seja respeitado e cumprido. Além da legislação, o envolvimento da equipe escolar é essencial para oferecer o suporte necessário para vencer barreiras, sejam elas arquitetônicas, de comunicação e atitudinais, e que resultem em ações positivas sempre favorecendo a inclusão de todos.

O professor é o grande protagonista inclusivo, dado que a sua postura perante a diferença altera todo o processo educacional. O seu trabalho é buscar sempre novas alternativas de ensino para promover a aprendizagem, fazendo com que o aluno se sinta cada vez mais capaz de realizar tarefas e ganhar autonomia, compartilhando novas experiências e desafios a serem vencidos.

A construção de um professor inclusivo é um processo gradativo. É nas suas vivências escolares, que ele tem a oportunidade de colocar em prática teorias que talvez só tenha tido contato em seus estudos. Nem sempre essas vivências favorecem uma postura inclusiva e podem até mesmo acarretar o preconceito ao que é diferente, estereotipando o indivíduo. Por esse motivo, a formação profissional do professor deve, na medida do possível, prepará-los para questionar e desafiar um ambiente escolar excludente.

Com a desconstrução dos estereótipos, o indivíduo tem a oportunidade de construir um relacionamento fora dos parâmetros preconceituosos produzidos socialmente, sem essa desconstrução, o indivíduo é engessado em sua particularidade. Com isso, perde suas características básicas como sexo, idade, gostos pessoais, para ser identificado apenas pelo que o torna diferente. Essa ação prejudica tanto o indivíduo estereotipado, quanto o preconceituoso, pois extingue a possibilidade de compreensão e experiências mútuas.

A maneira com que o professor conduz a experiência da inclusão acarreta em exemplo a todos seus alunos. Portanto, um professor empenhado a construir uma escola para todos possibilita a experiência de reconstrução a partir do outro. É de suma importância que o professor deixe as idealizações de lado e busque o autoconhecimento e o reconhecimento de si no outro, passando a pensar na aprendizagem não apenas na sua dimensão individual, mas de forma coletiva para que todos sejam valorizados.

\section{REFERÊNCIAS}

ANTUNES, C. Inclusão: o nascer de uma nova pedagogia. 2. ed. São Paulo: Principis, 2011. 89 p.

APAE BRASIL (Brasil). Federação Nacional das Apaes (Org.). História: Fenapaes, rede Apae e sua história. [2017]. Disponível em: <https://apaebrasil.org.br/page/2>. Acesso em: 10 jun. 2017

ASSEMBLÉIA GERAL DAS NAÇÕES UNIDAS (Org.). Programa de ação mundial para as pessoas com deficiência. 1982. Disponível em:

<http://www.todosnos.unicamp.br:8080/lab/legislacao/legislacao-internacional/PROGRAMA 
DE ACÃO MUNDIAL PARA AS PESSOAS COM DEFICIÊNCIA.doc/view>. Acesso em: 10 jun. 2017.

ASSEMBLÉIA GERAL DAS NAÇÕES UNIDAS. Convenção sobre os direitos da criança. 1989. Disponível em: 〈https://www.unicef.org/brazil/pt/resources_10120.htm>. Acesso em: 10 jun. 2017.

BRASIL. CAMARA DOS DEPUTADOS. (Org.). Lei no 4.024, de 20 de dezembro de 1961. 1961. Disponível em: <http://www2.camara.leg.br/legin/fed/lei/1960-1969/lei-4024-20dezembro-1961-353722-publicacaooriginal-1-pl.html>. Acesso em: 10 jun. 2017.

BRASIL. CONSELHO NACIONAL DE EDUCAÇÃO. (Org.). Diretrizes Curriculares Nacionais para a Formação de Professores da Educação Básica, em nível superior, curso de licenciatura, de graduação plena. 2002. Disponível em:

<http://portal.mec.gov.br/cne/arquivos/pdf/rcp01_02.pdf>. Acesso em: 24 jun. 2017

BRASIL. GOVERNO DO BRASIL. (Org.). Estatuto da criança e do adolescente completa 22 anos com avanços nos direitos. 2012. Disponível em:

$<$ http://www.brasil.gov.br/cidadania-e-justica/2012/07/vinte-e-dois-anos-de-estatuto-dacrianca-e-do-adolescente >. Acesso em: 10 jun. 2017.

BRASIL. Grupo de Trabalho Nomeado Pela Portaria Ministerial No 555. Mec/seesp (Org.). Política Nacional de Educação Especial na Perspectiva da Educação Inclusiva. 2007. Disponível em: <http://portal.mec.gov.br/seesp/arquivos/pdf/politica.pdf>. Acesso em: 24 jun. 2017.

BRASIL. MINISTÉRIO DA EDUCAÇÃO. (Org.). Conheça o INES. 2015. Disponível em: <http://www.ines.gov.br/conheca-o-ines/43-institucional>. Acesso em: 10 jun. 2017.

BRASIL. MINISTÉRIO DA EDUCAÇÃO. (Org.). Convenção interamericana para a eliminação de todas as formas de discriminação contra as pessoas portadoras de deficiência. 1999. Disponível em:

<http://portal.mec.gov.br/seesp/arquivos/pdf/guatemala.pdf>. Acesso em: 17 jun. 2017

BRASIL. MINISTÉRIO DA EDUCAÇÃO. (Org.). O IBC. 2016. Disponível em: <http://www.ibc.gov.br/o-ibc>. Acesso em: 10 jun. 2017.

BRASIL. MINISTÉRIO DA EDUCAÇÃO. (Org.). Planejando a próxima

década: conhecendo as 20 metas do plano nacional de educação. 2014. Disponível em: <http://pne.mec.gov.br/images/pdf/pne_conhecendo_20_metas.pdf>. Acesso em: 24 jun. 2017.

BRASIL. Ministério da Educação. Secretaria de Educação Especial (Org.). Projeto escola viva: garantindo acesso e permanência de todos os alunos na escola. 2005. Disponível em: <http://portal.mec.gov.br/seesp/arquivos/pdf/visaohistorica.pdf>. Acesso em: 08 out. 2017. 
BRASIL. Ministério da Educação. Secretaria de Educação Especial (Org.). Programa educação inclusiva: direito a diversidade: a fundamentação filosófica. 2004. Disponível em: 〈http://portal.mec.gov.br/seesp/arquivos/pdf/fundamentacaofilosofica.pdf >. Acesso em: 17 jun. 2017.

BRASIL. P. Casa Civil (Org.). Lei no 9.394, de 20 de dezembro de 1996. 1996. Disponível em: <http://www.planalto.gov.br/ccivil_03/leis/L9394.htm>. Acesso em: 17 jun. 2017.

BRASIL. PORTAL BRASIL. (Org.). Declaração universal dos direitos humanos garante igualdade social. 2009. Disponível em: <http://www.brasil.gov.br/cidadania-ejustica/2009/11/declaracao-universal-dos-direitos-humanos-garante-igualdade-social>. Acesso em: 10 jun. 2017.

BRASIL. PRESIDÊNCIA DA REPÚBLICA. (Org.). Decreto no 3.956, de 8 de outubro de 2001. 2001. Disponível em: <http://www.planalto.gov.br/ccivil_03/decreto/2001/d3956.htm>. Acesso em: 17 jun. 2017.

BRASIL. PRESIDÊNCIA DA REPÚBLICA. (Org.). Lei no 10.172, de 9 de janeiro de 2001. 2001. Disponível em:

<http://www.planalto.gov.br/ccivil_03/leis/leis_2001/110172.htm>. Acesso em: 17 jun. 2017

BRASIL. PRESIDÊNCIA DA REPÚBLICA. (Org.). Plano de Metas Compromisso Todos pela Educação. 2007. Disponível em: <http://www.planalto.gov.br/ccivil_03/_ato20072010/2007/decreto/d6094.htm>. Acesso em: 24 jun. 2017.

BRASIL. Presidência da República. Casa Civil (Org.). Constituição da República Federativa do Brasil de 1988. 1988. Disponível em:

<http://www.planalto.gov.br/ccivil_03/Constituicao/Constituicao.htm>. Acesso em: 10 jun. 2017.

BRASIL. Senado Federal. Secretaria de Informação Legislativa (Org.). Decreto $\mathbf{n}^{\mathbf{0}} \mathbf{7 2 . 4 2 5}$, de 3 de julho de 1973.1973. Disponível em:

<http://legis.senado.gov.br/legislacao/ListaPublicacoes.action?id=202007>. Acesso em: 10 jun. 2017.

BRITO, Nazineide. Educação inclusiva e o (des)preparo do professor: breves considerações. 2003. Disponível em:

$<$ https://sigaa.ufrn.br/sigaa/public/docente/producao.jsf?siape=6349952>. Acesso em: 16 set. 2017.

CONFERÊNCIA MUNDIAL SOBRE EDUCAÇÃO PARA TODOS (Org.). Declaração mundial sobre educação para todos: conferência de Jomtien- 1990. 1990. Disponível em: <https://www.unicef.org/brazil/pt/resources_10230.htm>. Acesso em: 17 jun. 2017.

CROCHÍK, J. L. Educação inclusiva e preconceito: desafios para a prática pedagógica. In: MIRANDA, Theresinha Guimarães; GALVÃO FILHO, Teófilo Alves (Org.). O professor e a educação inclusiva: formação, práticas e lugares. Salvador: Edufba, 2012. Cap. 3. p. 39-59. 
CROCHÍK, J. L. PRECONCEITO E INCLUSÃO. 2011. Disponível em:

<www.seer.ufrgs.br/webmosaica/article/download/22359/13016>. Acesso em: 10 jul. 2017.

CROCHÍK, J. L. Preconceito: indivíduo e cultura. 2. ed. São Paulo: Robe Editora, 1997. 152 p.

FERNANDES, S. Fundamentos para educação especial. 20. ed. Curitiba: IBPEX, 2007. $102 \mathrm{p}$.

FREIRE, P. Pedagogia do oprimido. 60. ed. Rio de Janeiro: Paz e Terra, 2016. 284 p.

INSTITUTO PESTALOZZI (Org.). Quem somos. [2017]. Disponível em:

<http://www.pestalozzi-canoas.org.br/instituto-pestalozzi.php>. Acesso em: 10 jun. 2017.

LAJONQUIÈRE, L. Duas notas psicanalíticas sobre as crianças "com necessidades educativas especiais".Disponível em:

<http://www3.fe.usp.br/secoes/inst/novo/acervo_lajonquiere/PDF_SWF/272.pdf >. Acesso em: 05 maio 2017.

MANTOAN, M. T. E. A educação especial no Brasil: da exclusão à inclusão escolar. [2017]. Disponível em: 〈http://www.lite.fe.unicamp.br/cursos/nt/ta1.3.htm>. Acesso em: 10 jun. 2017.

MANTOAN, M. T. E. Inclusão escolar - Oque é? Por quê? Como fazer? São Paulo: Moderna, 2006.

STAINBACK, S.; STAINBACK, W. Inclusão: um guia para educadores. 2. ed. Porto Alegre: Artmed, 1999. $451 \mathrm{p}$.

TODOS PELA EDUCAÇÃO (Brasil) (Org.). Conheça o histórico da legislação sobre a inclusão. 2014. Disponível em: <http://www.todospelaeducacao.org.br/reportagenstpe/31129/conheca-o-historico-da-legislacao-sobre-inclusao>. Acesso em: 17 jun. 2017.

Publicado em 26/11/2019. 